\title{
Molecular Pathogenesis and Immune Evasion of Vesicular Sto- matitis Virus Inferred from Genes Expression Changes in In- fected Porcine Macrophages
}

Lauro Velazquez-Salinas ${ }^{1,2}$, Jessica A. Canter ${ }^{1,2}$, James J. Zhu ${ }^{1^{*}}$ and Luis L. Rodriguez ${ }^{1^{*}}$

1 Foreign Animal Disease Research Unit, Plum Island Animal Disease Center, United States Department of Agriculture-Agricultural Research Service, Greenport, NY, United States; Lauro.velazquez@usda.gov Jessica.Canter@usda.gov James.Zhu@usda.gov Luis.Rodriguez@usda.gov

2 Plum Island Animal Disease Center Research Participation Program, Oak Ridge Institute for Science and Education, Oak Ridge, TN, United States; Lauro.velazquez@usda.gov Jessica.Canter@usda.gov

* Correspondence: James.Zhu@usda.gov (J.J.Z) Luis.Rodriguez@usda.gov (L.L.R) Tel.: Tel: 631-323-3340, FAX: 631-323-3006

Abstract: Molecular mechanisms associated with the pathogenesis of Vesicular stomatitis virus (VSV) in livestock remain poorly understood. Several studies have highlighted the relevant role of macrophages in controlling the systemic dissemination of VSV during infection in different animal models, including mice, cattle and pigs. To gain more insight on the molecular mechanisms used by VSV to impair the immune response in macrophages, we used microarrays to determine the transcriptomic changes produced by VSV infection in primary cultures of porcine macrophages. The results indicated that VSV infection induced the massive expression of multiple anorexic, pyrogenic, proinflammatory and immunosuppressive genes. Overall, the interferon (IFN) response appeared suppressed, leading to the absence of stimulation of interferon-stimulated genes (ISG). Interestingly, VSV infection promoted the expression of several genes known to downregulate the expression of IFN $\beta$. This represents an alternate mechanism for VSV control of the IFN response, beyond the recognized mechanisms mediated by the matrix protein. Although there was no significant differential gene expression in macrophages infected with a highly virulent epidemic strain compared to a less virulent endemic strain, the endemic strain consistently induced higher expression of all upregulated cytokines and chemokines. Collectively, this study provides novel insights into VSV molecular pathogenesis and immune evasion that warrants further investigation. 
Keywords: Vesicular Stomatitis Virus; macrophage; microarray analysis; differential gene expression; molecular pathogenesis; immune evasion

\section{Introduction}

Vesicular stomatitis virus (VSV) infection causes fever and vesicular stomatitis, one of four clinically indistinguishable viral vesicular diseases. VSV (family Rhabdoviridae, genus Vesiculovirus) is comprised of a non-segmented RNA viral genome encoding five structural proteins: nucleocapsid $(\mathrm{N})$, phosphoprotein $(\mathrm{P})$, matrix $(\mathrm{M})$, glycoprotein $(\mathrm{G})$, and the large RNAdependent RNA polymerase $(\mathrm{L})(1,2)$ along with two non-structural proteins $(\mathrm{C}$ and $\mathrm{C} 0)$ of undetermined function encoded in overlapping reading frames of the P gene (3). VSV causes most of the cases of vesicular diseases reported in livestock resulting in economic losses associated to quarantines imposed by animal health authorities due to its similar clinical presentation with foot and mouth disease virus (FMDV) $(4,5)$.

VSV has a broad host range and cell tropism due to its glycoprotein binding to host LDLR family members that are ubiquitously expressed on host cells and conserved among mammalian species $(6,7)$. Besides typical vesicular lesions in specific tissues, infected animals also show systemic signs such as anorexia, lethargy and fever (https://en.wikivet.net/Vesicular_Stomatitis_Virus). Despite these clinical signs, VSV infection typically does not result in host mortality $(4,5)$. After infection via insect bites, animals show limited virus replication, primarily in specific tissues where the vesicular lesions occur. Infected animals usually recover completely within 2-3 weeks of infection $(4,5)$.

Unlike gross pathogenesis, the molecular pathogenesis of VSV is not very clear. Based on literature review, it appears that only TNF has been investigated in VSV pathogenesis, showing more rapid induction of TNF by an attenuated VSV mutant after infection, but more drastic TNF induction later in infection by wildtype VSV in mice (8). TNF knockout mice showed diminished weight loss following wildtype VSV infection, and the rapid weight loss seen in wildtype VSV infection was less pronounced in C57BL/6 mice infected by an attenuated mutant virus (8). In mice, interferons produced by VSV-infected macrophages play a key role in protection against neuropathogenesis of the virus (9). In the natural hosts such as cattle, VSV antigens were colocalized with an antibody against a marker molecule (MAC387, MRP14 or S100A9) of myeloid cells including macrophages using immunohistochemistry (10). Both wildtype VSV and matrix protein mutants productively replicate in porcine immune cells and non-immune cells $(11,12)$. Infection with wildtype VSV induced weaker proinflammatory cytokine responses and downregulated the expression of the costimulatory molecule complex CD80/86 and MHC class II 
compared to the matrix protein mutant virus (11). A matrix protein (M51R) VSV mutant virus replicated 1000 times less in cultured primary porcine macrophages than its wildtype counterpart and showed significantly diminished virulence in pigs (13). The molecular pathogenesis and immune evasion in natural hosts such as pigs and cattle have yet to be investigated.

It is well-known that VSV can inhibit the host interferon response primarily via its matrix proteins $(14,15)$. VSV matrix protein mRNA can be translated into three proteins starting at three in-frame start codons (16). Transfection with plasmids containing the M protein gene alone can induce CPE in transfected cells (16). VSV M proteins can delay apoptosis induced by other viral components (17) and suppress transcription in infected cells by inhibiting the basal transcription factors TFIID and TFIIH and interacting with host Rae1 and Nup98 (18, 19, 20, 21, 22). VSV M proteins can also inhibit nuclear export of host mRNA and snRNAs (23) and NFkB activation (24). The suppression of IFN $\beta$ expression by the matrix protein is correlated with the inhibition of host RNA and protein synthesis (25). A systems biology approach including transcriptomic analysis has been conducted to study VSV infection in a murine macrophage cell line (26, 27 ); however, VSV pathogenesis and immune evasion were not explicitly explored based on transcriptional changes after virus infection. Although mice have been extensively used as an experimental model for VSV infection, they are not natural hosts for VSV infection. The transcriptomic analysis of VSV infection has not been investigated in the primary macrophages of its natural livestock hosts .

Macrophages play an important role in host defense against pathogens via positioning in all tissues where they can effectively sense danger signals with highly expressedPAMP receptors and producing a large quantity of both pro- and anti-inflammatory cytokines such as IL-1, IL-10, TGF $\beta$ and TNF via cell polarization and differentiation to regulate the immune response (28). Our previous study showed that primary porcine macrophages expressed higher levels of IFN $\beta$ and cytokines than primary fetal porcine kidney cell cultures after VSV infection (13). Given that VSV can infect and replicate in macrophages and the important role of macrophages in the immune response, ex vivo porcine macrophages were used as model cells to extrapolate the molecular mechanisms of VSV pathogenesis and immune evasion. The objective of this study was to formulate hypotheses for the molecular mechanisms of VSV pathogenesis and immune evasion based on gene expression changes in porcine macrophages after infection for further investigation.

\section{Results}

\subsection{Differential gene expression}


There were no genes differentially expressed between macrophages infected with epidemic VS New Jersey (NJ0612NME6) and endemic New Jersey (NJ0806VCB) strains (minimal FDR $=0.13$ ). There was a total of 4,346 significant differentially expressed genes at a false-discovery rate (FDR) of $\leq 0.05$ with at least a $50 \%$ difference and a total of 3,345 with a difference of 2-fold or greater between epidemic VSV and mock infected macrophages. Between epidemic VSV and mock infected macrophages, there were a total of 3,345 significant differentially expressed genes (DEG) by at least $50 \%$ at a false-discovery rate (FDR) of $\leq 0.05$. Among these DEG, the majority were detected as being downregulated (2,179 DEG) compared to 1,166 upregulated genes between VSV-infected and mockinfected cells, which was at approximately 2:1 ratio. Forty four percent of DEG were differentially expressed by 1.5- to 2.0-fold with 841 of these genes being downregulated, and 618 being upregulated (Figure 1). There were 54\% of DEG with a fold change between 2.0 and 5.0, and the largest proportion of genes, 1288, were downregulated compared to 521 genes upregulated. Finally, the remaining $2.3 \%$ of the DEG were differentially expressed with a fold change greater than 5 ( 27 genes downregulated and 50 genes upregulated) (Figure 1). The most drastic differences were at a fold change of 10.2 for a downregulated gene, and 32.8 for an upregulated gene between these VSV- and mock-infected macrophages.

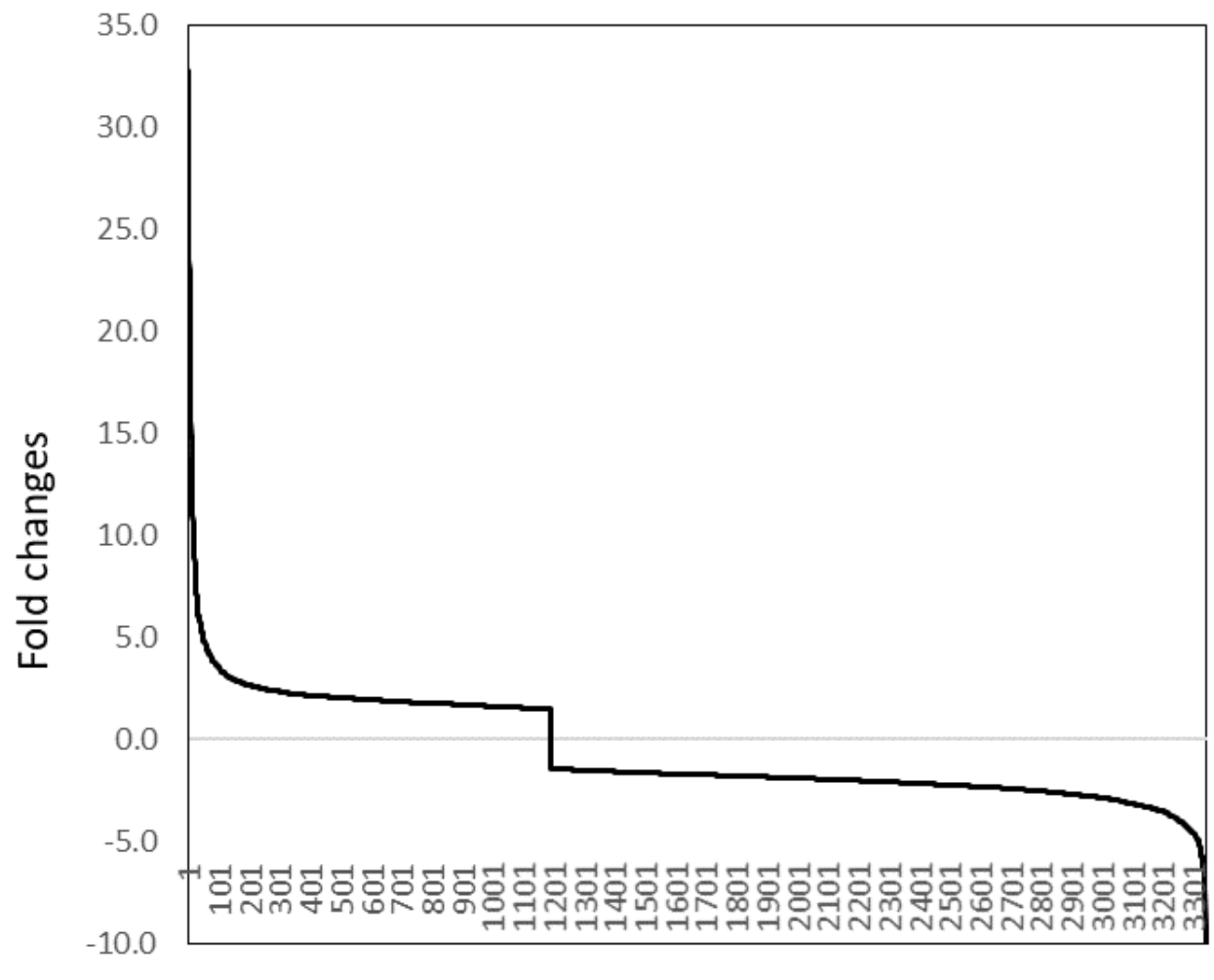

Differentially expressed genes 
Figure 1. The distribution of fold-changes of annotated genes with significantly differential expression equal to or greater than 2-fold between VSV- and mock-infected macrophages from most upregulated (32.8-fold) to most downregulated (-10.2-fold) genes in VSV-infected macrophage compared to mock-infection

\subsection{Pathway analyses}

To identify biological pathways/processes most impacted by the differential expression, the lists of DEG with differential expression of a fold change of at least 2-fold to remove DEG with minor effects were used in the DAVID analysis. GO term analysis showed that NFkB signaling pathway was the most over-represented by the DEG with three other significant biological processes in protein ubiquitination, Toll-like receptor signaling, and mRNA transcription regulation (Table 1). KEGG pathway analysis identified eleven over-represented biological pathways with top five pathways (TNF, TLR, NFkB, RIG-I-like receptor, and NOD-like receptor signaling) that are known to play key roles in the immune response (Table 1). Only one biological pathway (TNFinduced apoptosis) was detected with REACTOME analysis.

When this list of DEG was further narrowed to those with a fold change of at least 4 (more biologically impactful DEG), GO term analysis identified thirteen over-represented biological processes; six involved in the immune response, four in apoptosis, two in signaling pathways and one in RNA transcription. The two most over-represented GO terms were in inflammatory response (GO_0006954) and apoptotic process (GO_0006915) (Table 1). The significant over-represented KEGG pathways included: KEGG_hsa04060-Cytokine-cytokine receptor interaction; KEGG_hsa04668-TNF-signaling pathway; KEGG_hsa04064-NF-kappa B-signaling pathway; KEGG_hsa04621- NOD-like receptor signaling pathway and KEGG_hsa04620- Toll-like receptor signaling pathway. Only one Reactome pathway (HSA-380108: Chemokine receptors bind chemokines) was significant.

\begin{tabular}{|c|c|c|c|}
\hline & Pathway analysis & Count & Benjamini \\
\hline \multirow{8}{*}{ 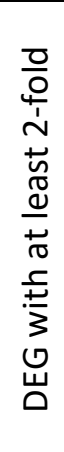 } & GO_0007249: I-kappaB kinase/NF-kappaB signaling & 23 & 8.20E-05 \\
\hline & GO_0016567: protein ubiquitination & 62 & 0.026 \\
\hline & GO_0035666: TRIF-dependent toll-like receptor signaling pathway & 12 & 0.036 \\
\hline & GO_0045944: positive regulation of transcription by RNA polymerase II & 135 & 0.045 \\
\hline & :KEGG_hsa04668: TNF signaling pathway & 34 & $6.40 \mathrm{E}-07$ \\
\hline & KEGG_hsa04620: Toll-like receptor signaling pathway & 33 & $1.01 \mathrm{E}-06$ \\
\hline & !KEGG_hsa04064: NF-kappa B signaling pathway & 28 & $5.35 \mathrm{E}-06$ \\
\hline & KEGG_hsa04622: RIG-I-like receptor signaling pathway & 21 & 5.73E-04 \\
\hline
\end{tabular}




\begin{tabular}{|c|c|c|c|}
\hline & KEGG_hsa04621: NOD-like receptor signaling pathway & 16 & 0.011 \\
\hline & KEGG_hsa04144: Endocytosis & 43 & 0.012 \\
\hline & KEGG_hsa05160: Hepatitis C & 27 & 0.022 \\
\hline & KEGG_hsa05169: Epstein-Barr virus infection & 25 & 0.026 \\
\hline & KEGG_hsa04210: Apoptosis & 16 & 0.029 \\
\hline & KEGG_hsa05220: Chronic myeloid leukemia & 17 & 0.043 \\
\hline & KEGG_hsa04140: Regulation of autophagy & 9 & 0.050 \\
\hline & REACTOME_HSA-5357786: TNFR1-induced proapoptotic signaling & 8 & 0.039 \\
\hline & GO_0006954: inflammatory response & 19 & 1.19E-05 \\
\hline & GO_0006915: apoptotic process & 20 & $5.38 \mathrm{E}-04$ \\
\hline & GO_0045944: positive regulation of transcription by RNA polymerase II & 25 & 0.003 \\
\hline$\cdot \frac{\circ}{\sqrt{\omega}}$ & GO_0006955: immune response & 15 & 0.009 \\
\hline$\frac{\varrho}{2}$ & GO_0043065: positive regulation of apoptotic process & 12 & 0.019 \\
\hline$\stackrel{x}{a}$ & GO_0071222: cellular response to lipopolysaccharide & 8 & 0.020 \\
\hline$\stackrel{\text { : }}{\stackrel{D}{C}}$ & GO_0051897: positive regulation of protein kinase B signaling & 7 & 0.021 \\
\hline$\frac{\square}{\square}$ & GO_0042981: regulation of apoptotic process & 10 & 0.022 \\
\hline & GO_0070373: negative regulation of ERK1 and ERK2 cascade & 6 & 0.026 \\
\hline$\frac{0}{0}$ & GO_2001244: positive regulation of intrinsic apoptotic signaling pathway & 5 & 0.029 \\
\hline$\overbrace{}^{1}$ & GO_0030593: neutrophil chemotaxis & 6 & 0.036 \\
\hline$\stackrel{\pi}{\mathscr{O}}$ & GO_0051384: response to glucocorticoid & 6 & 0.037 \\
\hline$+\pi$ & GO_0070098: chemokine-mediated signaling pathway & 6 & 0.047 \\
\hline$\frac{+}{3}$ & KEGG_hsa04060: Cytokine-cytokine receptor interaction & 15 & $3.82 \mathrm{E}-05$ \\
\hline 㞻 & KEGG_hsa04668: TNF signaling pathway & 11 & 4.69E-05 \\
\hline & KEGG_hsa04064: NF-kappa B signaling pathway & 7 & 0.016 \\
\hline & KEGG_hsa04621: NOD-like receptor signaling pathway & 6 & 0.020 \\
\hline & KEGG_hsa04620: Toll-like receptor signaling pathway & 7 & 0.027 \\
\hline & Reactome-HSA-380108: Chemokine receptors bind chemokines & 7 & 0.003 \\
\hline
\end{tabular}

Table 1. Gene ontology terms, Kyoto Encyclopedia of Genes and Genomes (KEGG) and REACTOME biological pathways over-represented by genes differentially expressed by at least 2- and 4-fold between VSV-infected and mockinfected porcine macrophages using the NCBI DAVID program with Benjamini p-value correction

\subsection{Interferon expression and signaling}

VSV infection significantly induced the expression of IFNB by 6.2-fold, but not other interferons, in infected macrophages compared to mock-infected cells (Table 2). The endemic strain induced higher IFNB expression (2-fold) than the epidemic strain but not at the significant level. VSV infections significantly suppressed the expression of an IFNA homologous to human IFNA17 by approximately 2-fold and did not significantly alter expression of other interferons including types II and III. The expression of type I (IFNAR1 and IFNAR2) and II (IFNGR1) receptors were suppressed in VSV-infected cells compared to mock-infection (Table 2). The type III IFN receptor (IFNLR1) was 
expressed at a very low level in the macrophages (signal intensity $=69$, SNR $<2$ ). The expression of typical interferon stimulated genes (ISGs) was not significantly changed by VSV-infection (only 10 genes listed in Table 2). These results indicate that VSV infection suppressed type I IFN and II IFN signaling.

Six genes, AHR (30, 31), ATF3 (32), DUSP1 (33), FOS (34), HES1 (35) and PRDM1 (36) known to negatively regulate type I IFN expression were significantly induced mostly by > 10-fold in VSVinfected cells (Table 2). Among all DEG, PRDM1 was the most induced gene ( 33-fold higher) after infection and FOS was the fifth most-induced gene in this study (Table 7). EGR1, a PRDM1 expression inducing gene (37), was also highly upregulated (13.4-fold) in VSV infected cells. These results indicate that VSV infection induces expression of genes suppressing IFNB expression.

\begin{tabular}{|c|c|c|c|c|c|c|}
\hline Group & Gene & EXP & EP/M & FDR & EP/EN & FDR \\
\hline \multirow{5}{*}{ 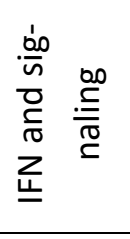 } & IFNA17 & 77 & -1.9 & 0.01 & -1.1 & 0.96 \\
\hline & IFNB & 179 & 6.2 & 0.04 & -2.1 & 0.79 \\
\hline & IFNAR1 & 3774 & -2.0 & 0.01 & 1.0 & 0.97 \\
\hline & IFNAR2 & 2223 & -2.9 & 0.03 & -1.2 & 0.90 \\
\hline & IFNGR1 & 1000 & -2.7 & 0.02 & -1.2 & 0.92 \\
\hline \multirow{10}{*}{ 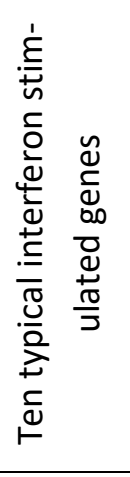 } & IFI44L & 955 & 1.1 & 0.88 & 1.2 & 0.82 \\
\hline & IFIH1 & 107 & -1.1 & 0.92 & -1.0 & 1.00 \\
\hline & IFIT1 & 231 & 1.7 & 0.52 & -1.4 & 0.89 \\
\hline & IFIT2 & 420 & -2.4 & 0.23 & 1.0 & 0.99 \\
\hline & IFIT3 & 3298 & -1.6 & 0.27 & 1.2 & 0.89 \\
\hline & IFIT5 & 364 & -2.0 & 0.10 & 1.4 & 0.80 \\
\hline & ISG20 & 580 & 1.2 & 0.91 & 1.3 & 0.96 \\
\hline & MX1 & 3882 & -1.2 & 0.90 & -1.0 & 0.99 \\
\hline & MX2 & 1330 & -1.5 & 0.56 & 1.2 & 0.94 \\
\hline & OAS1 & 155 & -1.1 & 0.95 & 1.1 & 0.98 \\
\hline \multirow{7}{*}{ 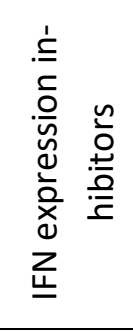 } & AHR & 193 & 6.1 & 0.01 & -1.0 & 0.98 \\
\hline & ATF3 & 1432 & 8.6 & 0.05 & -1.6 & 0.91 \\
\hline & DUSP1 & 2208 & 13.8 & 0.01 & -1.6 & 0.88 \\
\hline & EGR1 & 891 & 13.4 & 0.01 & -2.1 & 0.79 \\
\hline & FOS & 1993 & 22.9 & 0.01 & -1.7 & 0.90 \\
\hline & HES1 & 218 & 10.6 & 0.02 & -1.2 & 0.97 \\
\hline & PRDM1 & 796 & 32.8 & 0.01 & -1.9 & 0.86 \\
\hline
\end{tabular}


Table 2. Expression levels (EXP), false discovery rates (FDR) and fold differences (epidemic vs mock infection: EP/M, epidemic vs endemic infection: EP/EN) of interferon signaling genes differentially expressed between infected-, and/or mock-infected macrophages

\subsection{Immune signaling pathways}

The expression of a transcription factor (ATF2) and five MAPK kinases (MAP2K5, MAPK14/p38, MAPK4, and MAP3K18) in the MAPK signaling pathways was significantly downregulated in VSV infected cells compared to mock-infected cells (Table 3). Likewise, the expression of six activator genes (CARD6, IKBKB, IRAK1, NLK, TAB1, TAB2, and TAK1) in the NFkB pathway was significantly downregulated in VSV-infected cells, whereas the expression of three inhibitors of NFkB [NFKBIA, NFKBID, and TNFIP3/A20 (38) was significantly upregulated (Table 3). Three genes (IRF5, MAVS and TBK1) in the RIG-I signaling pathway were expressed at significantly higher levels in VSV-infected cells than in mock-infected cells (Table 3). The expression of four TLR receptors (TLR1, TLR2, TLR4 and TLR6) and two signal transducers (BTK and TRIF) was downregulated in VSV-infected cells compare to mock-infected cells, whereas TLR7 was upregulated (Table 3). These results indicate that VSV infection suppresses the signaling of MAPK, NFkB, RIG-I and TLR pathways.

\begin{tabular}{|c|c|c|c|c|c|c|}
\hline Pathway & Gene & EXP & $E P / M$ & FDR & EP/EN & FDR \\
\hline \multirow{5}{*}{$\frac{\frac{v}{a}}{\sum}$} & ATF2 & 300 & -2.4 & 0.01 & 1.3 & 0.75 \\
\hline & MAP2K5 & 1804 & -1.7 & 0.02 & 1.0 & 0.99 \\
\hline & MAPK14/p38 & 539 & -3.2 & 0.03 & 1.0 & 1.00 \\
\hline & MAPK4 & 176 & -2.8 & 0.02 & 1.4 & 0.79 \\
\hline & MAР3К18 & 2279 & -4.3 & 0.00 & 1.1 & 0.98 \\
\hline \multirow{10}{*}{ 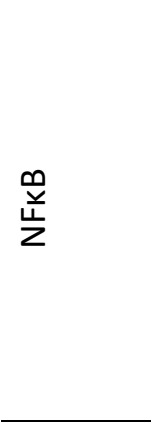 } & CARD6 & 404 & -2.6 & 0.01 & 1.1 & 0.95 \\
\hline & IKBKB & 907 & -2.2 & 0.01 & -1.0 & 0.99 \\
\hline & IRAK1 & 5234 & -3.5 & 0.00 & -1.0 & 0.98 \\
\hline & NLK/NEMO & 170 & -3.3 & 0.01 & 1.2 & 0.88 \\
\hline & TAB1 & 1817 & -2.2 & 0.03 & 1.1 & 0.98 \\
\hline & TAB2 & 416 & -2.7 & 0.00 & 1.1 & 0.91 \\
\hline & TAK1 & 440 & -2.1 & 0.01 & 1.2 & 0.80 \\
\hline & NFKBIA & 10873 & 7.9 & 0.01 & -1.2 & 0.95 \\
\hline & NFKBID & 1182 & 4.2 & 0.03 & -1.6 & 0.81 \\
\hline & TNFAIP3/A20 & 799 & 8.3 & 0.00 & -1.4 & 0.88 \\
\hline \multirow{3}{*}{$\frac{\bar{\sigma}}{\widetilde{\Phi}}$} & IRF5 & 3796 & -2.1 & 0.01 & -1.1 & 0.95 \\
\hline & MAVS & 452 & -2.1 & 0.03 & -1.1 & 0.95 \\
\hline & TBK1 & 459 & -2.0 & 0.05 & -1.1 & 0.97 \\
\hline \multirow{3}{*}{$\frac{1}{\overline{\bar{\sigma}}} \stackrel{\varrho}{\underline{\underline{\Xi}}} \stackrel{d}{\varrho}$} & BTK & 4636 & -2.0 & 0.01 & 1.2 & 0.82 \\
\hline & TLR1 & 361 & -2.8 & 0.02 & 1.2 & 0.93 \\
\hline & TLR2 & 11817 & -3.8 & 0.00 & -1.1 & 0.94 \\
\hline
\end{tabular}




\begin{tabular}{llllll}
\hline TLR4 & 543 & -3.8 & 0.01 & 1.0 & 0.99 \\
TICAM2/TRIF & 129 & -2.8 & 0.02 & 1.3 & 0.84 \\
TLR6 & 143 & -3.3 & 0.01 & 1.2 & 0.91 \\
TLR7 & 293 & 1.7 & 0.03 & 1.0 & 0.99 \\
\hline
\end{tabular}

Table 3. Expression levels (EXP), false discovery rates (FDR) and fold differences (epidemic vs mock infection: EP/M, epidemic vs endemic infection: $E P / E N$ ) of interferon expression regulating genes differentially expressed between infected-and/or mock-infected macrophages

\subsection{Cytokines, chemokines, and receptors}

VSV infection significantly induced the expression of five immune cytokines (CSF3, IL1A, IL10, IL27, TNF and TNFSF9) and suppressed TNFSF11 expression (Table 4). Four non-typical immune cytokines (AREG, HBEGF, LIF and VEGFA) were expressed at significantly higher levels in VSVinfected than mock-infected cells (Table 4). Among those cytokines, AREG, IL1A, IL10, LIF and TNF were upregulated by $>11$-fold. Overall, the endemic strain induced consistently higher expression (averaging 1.7-fold) of the upregulated cytokines than the epidemic strain though at not significant levels, whereas the receptor expression was very similar (Table 4). There were three significantly downregulated (IL17RA, LTBR and TNFRSF1A) and three upregulated (TNFRSF10, IL1R2 and IL20RB) cytokine receptors in VSV-infected cells compared to mock-infected cells (Table 4). All these DEG are proinflammatory genes with the exception of IL10, IL1R2, IL20RB, and the four non-typical immune cytokines. These results show that VSV infection induced both pro- and anti-inflammatory cytokine expression and suppressed the expression of IL-17 and TNF receptors.

VSV infection significantly induced expression of seven chemokines (CCL3, CCL4, CCL5, CCL20, CXCL1, CXCL2 and CXCL3) by 3- to 42-fold compared to mock infection (Table 5). As for cytokines, the endemic strain also induced higher expression of the upregulated chemokines by 1.6fold than the epidemic strain though not significant and nearly identical receptor expression (Table 5). The expression of three chemokine receptors [CCR5 (the receptor of CCL3, CCL4 and CCL5), CCLRL2 and CX3CR1] was significantly downregulated by VSV infection (Table 5), whereas CCR7 and CXCR4 expression was significantly induced after VSV infection when compared to mock-infected cells (Table 5). The results suggest that chemokines upregulated by VSV infection could cause infiltration of neutrophils, macrophages and Th17 cells in the infected tissue according to their chemotactic activities (39). On other hand, the infection could also alter the response of the infected cells to chemokines. 


\begin{tabular}{|c|c|c|c|c|c|c|}
\hline Group & Gene & EXP & $E P / M$ & FDR & EP/EN & FDR \\
\hline \multirow{12}{*}{ 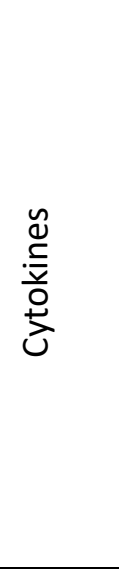 } & CSF3 & 750 & 4.0 & 0.05 & -1.3 & 0.93 \\
\hline & IL1A & 698 & 13.9 & 0.02 & -1.9 & 0.87 \\
\hline & IL1B & 1793 & 7.7 & 0.13 & -1.7 & 0.92 \\
\hline & IL10 & 1109 & 11.5 & 0.00 & -1.9 & 0.76 \\
\hline & IL27 & 318 & 3.8 & 0.01 & -1.9 & 0.67 \\
\hline & TNF & 2641 & 23.4 & 0.01 & -1.7 & 0.87 \\
\hline & TNFSF9/CD137L & 369 & 5.2 & 0.02 & -2.4 & 0.66 \\
\hline & TNFSF11 & 729 & -4.5 & 0.02 & 1.2 & 0.94 \\
\hline & AREG & 258 & 17.5 & 0.01 & -1.6 & 0.91 \\
\hline & HBEGF & 673 & 4.7 & 0.04 & -1.3 & 0.94 \\
\hline & LIF & 217 & 12.9 & 0.01 & -1.9 & 0.79 \\
\hline & VEGFA & 384 & 5.7 & 0.03 & -1.6 & 0.86 \\
\hline \multirow{5}{*}{ 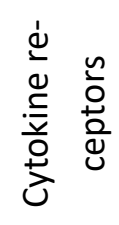 } & IL1R2 & 219 & 2.9 & 0.04 & -1.3 & 0.88 \\
\hline & IL17RA & 4899 & -1.7 & 0.02 & 1.0 & 0.98 \\
\hline & IL20RB & 92 & 2.7 & 0.03 & -1.4 & 0.80 \\
\hline & LTBR & 8211 & -3.5 & 0.01 & 1.1 & 0.95 \\
\hline & TNFRSF1A & 3943 & -2.3 & 0.01 & -1.0 & 1.00 \\
\hline
\end{tabular}

Table 4. Expression levels (EXP), false discovery rates (FDR) and fold differences (epidemic vs mock infection: EP/M, epidemic vs endemic infection: $E P / \underline{E N}$ ) of cytokine, chemokine and the receptor genes differentially expressed between infected- and/or mock-infected macrophages

\begin{tabular}{|c|c|c|c|c|c|c|}
\hline Group & Gene & EXP & $E P / M$ & FDR & EP/EN & FDR \\
\hline \multirow{5}{*}{$\stackrel{u}{u}$} & $\mathrm{CCL} 3$ & 2336 & 7.4 & 0.01 & -1.8 & 0.80 \\
\hline & CCL4 & 3028 & 29.1 & 0.00 & -2.1 & 0.79 \\
\hline & CCL5 & 6487 & 3.1 & 0.06 & -1.4 & 0.88 \\
\hline & CCL5_v & 385 & 23.0 & 0.01 & -1.6 & 0.90 \\
\hline & CCL2O & 412 & 17.7 & 0.01 & -1.4 & 0.94 \\
\hline \multirow{3}{*}{ 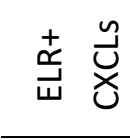 } & CXCL1 & 1791 & 6.4 & 0.03 & -1.1 & 0.98 \\
\hline & CXCL2 & 3008 & 21.2 & 0.00 & -1.9 & 0.81 \\
\hline & CXCL3 & 2388 & 6.8 & 0.02 & -1.5 & 0.90 \\
\hline \multirow{5}{*}{ 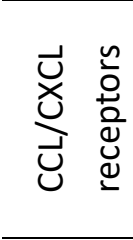 } & CCR5 & 246 & -2.8 & 0.02 & -1.0 & 1.00 \\
\hline & CCR7 & 206 & 4.5 & 0.00 & -1.3 & 0.84 \\
\hline & CCRL2 & 1839 & -1.8 & 0.02 & 1.1 & 0.94 \\
\hline & CX3CR1 & 129 & -2.2 & 0.02 & 1.1 & 0.92 \\
\hline & CXCR4 & 1060 & 4.3 & 0.02 & -1.1 & 0.98 \\
\hline
\end{tabular}

Table 5. Expression levels (EXP), false discovery rates (FDR) and fold differences (epidemic vs mock infection: EP/N, epidemic vs endemic infection: EP/EN) of chemokine and the receptor genes differentially expressed between infected- and/or mock-infected macrophages

\subsection{Apoptosis, autophagy, and unfold protein response}


The expression of three pro-apoptotic genes, BCL2L13 (40), DAPK1 (41) and DIDO1 (42) and a key caspase (CASP8) in the apoptosis activating pathway were significantly downregulated in VSV-infected macrophages (Table 6). On the other hand, two apoptosis inhibitors, BIRC3/cIAP2 and SGK1 (43) and an activator of the apoptosis inhibitor expression, REL (44), were upregulated (Table 6). Two negative regulator genes of TNF-induced apoptosis, BRE (45) and IER3 (46), were also downregulated in VSV-infected cells (Table 6).

The expression of eight autophagy-associated genes including seven ATGs and FLCN and positive autophagy regulator, ULK1 (47) and RB1CC1 (48) Rab33b (49) was significantly lower in VSV-infected cells than in mock-infected cells (Table 6). Two autophagy inhibitors, BCL2L11/BIM (50) and Gadd45b (51) were expressed at significantly higher levels in VSV-infected cells than in Mock-infected cells (Table 6). GADD45B was one of the top 10 most induced genes after VSV infection (Table 10).

The expression of XBP1, a key regulator in stress-induced unfolded protein response (UPR) (52) and ERN1, the ER stress sensor of UPR (53), were significantly downregulated in VSV-infected cells compared to mock-infected cells (Table 6). PPP1R15A (GADD34) mediates dephosphorylation of eIF2alpha in a negative feedback loop and inhibits the unfolded protein response (UPR) (54), and its expression was significantly upregulated by 7-fold in VSV infected macrophages compared to mock infection (Table 6). The results of gene expression changes after infection suggested that VSV suppresses apoptosis, autophagy, and the UPR response.

\begin{tabular}{|c|c|c|c|c|c|c|}
\hline Group & Gene & EXP & EP/MM & FDR & EP/EN & FDR \\
\hline \multirow{12}{*}{ 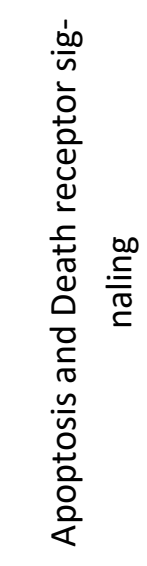 } & BCL2L13 & 1167 & -2.0 & 0.01 & 1.2 & 0.77 \\
\hline & CASP8 & 337 & -2.1 & 0.02 & 1.1 & 0.90 \\
\hline & DAPK1 & 246 & -2.2 & 0.01 & 1.1 & 0.96 \\
\hline & DIDO1 & 162 & -2.1 & 0.02 & 1.3 & 0.75 \\
\hline & BIRC3/CIAP2 & 656 & 3.5 & 0.01 & -1.2 & 0.90 \\
\hline & REL & 100 & 4.8 & 0.02 & -2.4 & 0.66 \\
\hline & SGK1 & 2392 & 4.1 & 0.01 & -1.4 & 0.86 \\
\hline & BRE & 184 & 2.9 & 0.05 & -2.0 & 0.68 \\
\hline & FADD & 145 & -2.2 & 0.04 & -1.0 & 1.00 \\
\hline & IER3 & 988 & 5.6 & 0.02 & -1.5 & 0.87 \\
\hline & RIPK1 & 1864 & -2.1 & 0.01 & -1.1 & 0.91 \\
\hline & TRADD & 3504 & -2.1 & 0.03 & -1.0 & 0.98 \\
\hline \multirow{6}{*}{ 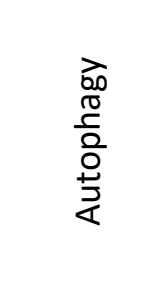 } & ATG3 & 2041 & -1.8 & 0.03 & 1.1 & 0.92 \\
\hline & ATG4B & 1154 & -2.8 & 0.01 & 1.0 & 0.99 \\
\hline & ATG5 & 524 & -2.1 & 0.05 & 1.2 & 0.88 \\
\hline & ATG9A & 977 & -2.2 & 0.00 & 1.1 & 0.96 \\
\hline & ATG16L1 & 351 & -2.3 & 0.01 & -1.3 & 0.72 \\
\hline & ATG16L2 & 1146 & -2.1 & 0.00 & -1.1 & 0.95 \\
\hline
\end{tabular}




\begin{tabular}{|c|c|c|c|c|c|c|}
\hline & ATG101 & 1026 & -2.7 & 0.01 & -1.1 & 0.95 \\
\hline & FLCN & 771 & -4.8 & 0.01 & -1.1 & 0.97 \\
\hline & RAB33B & 241 & -3.0 & 0.00 & 1.4 & 0.70 \\
\hline & RB1CC1 & 147 & -1.9 & 0.03 & 1.1 & 0.97 \\
\hline & ULK1 & 1083 & -1.8 & 0.03 & -1.1 & 0.96 \\
\hline & BCL2L11/BIM & 152 & 4.3 & 0.00 & -1.6 & 0.71 \\
\hline & GADD45B & 649 & 22.6 & 0.00 & -1.6 & 0.86 \\
\hline \multirow{3}{*}{ 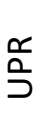 } & ERN1 & 146 & -2.6 & 0.02 & 1.0 & 0.99 \\
\hline & PPP1R15A & 850 & 7.0 & 0.01 & -1.5 & 0.85 \\
\hline & XBP1 & 4634 & -6.1 & 0.01 & 1.1 & 0.98 \\
\hline
\end{tabular}

Table 6. Expression levels (EXP), false discovery rates (FDR) and fold differences (epidemic vs mock infection: EP/M, epidemic vs endemic infection: EP/EN) of apoptosis-, autophagy-, and unfold protein response (UPR)-related genes differentially expressed between infected-and/or mock-infected macrophages

\subsection{Host mRNA transcription, modification, and stability}

Thirteen genes involved in transcription of host RNA based on KEGG pathways were significantly downregulated in VSV-infected cells compared to mock-infected macrophages (Table 7). The expression of five genes [CMTR2 (mRNA cap methylation), DICER1 (microRNA processing), MIR132 (microRNA), TIAL1 (selective binding to several mRNAs to control expression of translation regulatory proteins) (55) and ZFP36/TTP (AT-rich mRNA degradation) (56) in post-transcriptional mRNA processing were significantly affected by VSV infection being the first two downregulated and the last two upregulated, respectively (Table 7). These results suggested that host mRNA transcription and processing could be negatively impacted by VSV infection to facilitate VSV replication.

\begin{tabular}{|c|c|c|c|c|c|c|}
\hline Group & Gene & EXP & $E P / M$ & FDR & EP/EN & FDR \\
\hline \multirow{13}{*}{ 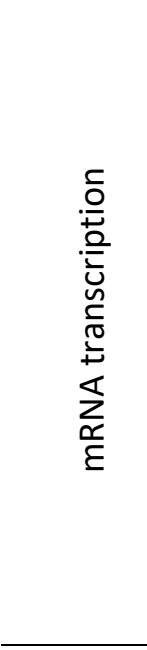 } & CDK7 & 359 & -3.1 & 0.01 & 1.2 & 0.91 \\
\hline & GTF2A1 & 534 & -2.5 & 0.00 & 1.3 & 0.72 \\
\hline & GTF2B & 1429 & -2.2 & 0.05 & 1.2 & 0.92 \\
\hline & GTF2E1 & 176 & -2.2 & 0.02 & 1.1 & 0.97 \\
\hline & MNAT1 & 217 & -1.7 & 0.03 & 1.2 & 0.84 \\
\hline & RPAP3 & 161 & -1.6 & 0.05 & 1.0 & 0.99 \\
\hline & TAF1C & 481 & -3.1 & 0.03 & -1.2 & 0.94 \\
\hline & TAF7 & 716 & -2.7 & 0.01 & 1.2 & 0.89 \\
\hline & TAF11 & 882 & -3.2 & 0.03 & 1.1 & 0.97 \\
\hline & TBP & 1191 & -1.8 & 0.01 & 1.2 & 0.92 \\
\hline & TCEANC2 & 130 & -2.6 & 0.01 & 1.3 & 0.75 \\
\hline & TCF20 & 348 & -2.2 & 0.03 & -1.0 & 0.98 \\
\hline & TFCP2 & 248 & -1.9 & 0.01 & 1.1 & 0.91 \\
\hline \multirow{5}{*}{ 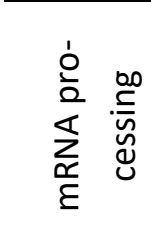 } & CMTR2 & 180 & -3.5 & 0.01 & 1.3 & 0.83 \\
\hline & DICER1 & 1024 & -2.4 & 0.02 & -1.1 & 0.98 \\
\hline & MIR132 & 78 & 3.3 & 0.03 & -2.7 & 0.54 \\
\hline & TIAL1 & 93 & -3.7 & 0.04 & -1.3 & 0.88 \\
\hline & ZFP36/TTP & 5049 & 4.5 & 0.03 & -2.0 & 0.74 \\
\hline
\end{tabular}


Table 7. Expression levels (EXP), false discovery rates (FDR) and fold differences (epidemic vs mock infection: EP/M, epidemic vs endemic infection: EP/EN) of transcription- and translation-related genes differentially expressed between infected- and/or mock-infected macrophages

\subsection{Inflammation-related genes}

Two proinflammatory mediator genes, ADM, (57), and a prostaglandin E (PGE) synthase (PTGS2) (58) were expressed at significantly higher levels (5.6 and 15.6 times, respectively) after VSV infection (Table 8). MALAT1 and DUSP2 play a role in prostaglandin E2 production in macrophages $(59,60)$, and their expression was also upregulated by VSV infection (Table 8). There were three C5a or purinergic receptor genes involved in macrophage M1 activation including C5AR1 (61), P2RY1 and P2RY6 (62) being downregulated and a suppressor (IL4I1) of macrophage M1 activation (63) upregulated in VSV-infected cells (Table 8).

A multitude of genes associated with pro-inflammatory responses were also differentially affected by VSV infection compared to mutant vs. mock infection (Table 8). Two genes MAP3K8 (64) and MEFV (65) critical for IL-1 and TNF production were upregulated in VSV infected cells. On the other hand, the expression of five proinflammatory genes, CEBPD (66). DUSP6 in macrophages enhances cytokine production (67), MAFB (68), MAPK8IP3/JIP3 (69) and MTRES1 (70) was downregulated. These results indicate VSV can alter host gene expression via both up- and downregulation of proinflammatory genes.

\begin{tabular}{l|lrrrrr}
\hline Group & Gene & EXP & EP/M & FDR & EP/EN & FDR \\
\multirow{3}{*}{ Inflammation } & ADM & 331 & 5.9 & 0.01 & -1.3 & 0.90 \\
mediator & DUSP2 & 2264 & 3.8 & 0.01 & -1.0 & 0.99 \\
& MALAT1 & 125 & 6.0 & 0.01 & -1.7 & 0.75 \\
& PTGS2 & 300 & 15.6 & 0.02 & -1.3 & 0.95 \\
\hline \multirow{3}{*}{ Macrophage } & C5AR1 & 10355 & -3.0 & 0.01 & 1.1 & 0.94 \\
activation & IL4I1 & 297 & 3.6 & 0.01 & -1.2 & 0.89 \\
& P2RY1 & 505 & -7.3 & 0.00 & 1.1 & 0.96 \\
& P2RY6 & 290 & -2.6 & 0.05 & 1.1 & 0.97 \\
\hline \multirow{5}{*}{ Immune stimulators } & MAP3K8 & 779 & 10.0 & 0.00 & -1.5 & 0.85 \\
& MEFV & 1158 & 6.7 & 0.03 & -1.7 & 0.85 \\
\cline { 2 - 7 } & CEBPD & 2210 & -9.3 & 0.02 & -1.1 & 0.99 \\
& DUSP6 & 4285 & -6.3 & 0.01 & 1.0 & 1.00 \\
& MAFB & 3002 & -10.0 & 0.00 & -1.3 & 0.91 \\
& MAPK8IP3/JIP3 & 1932 & -5.8 & 0.01 & 1.0 & 1.00 \\
& MTRES1 & 1804 & -9.7 & 0.00 & 1.2 & 0.93 \\
\hline
\end{tabular}


Table 8. Expression levels (EXP), false discovery rates (FDR) and fold differences (epidemic vs mock infection: EP/M, epidemic vs endemic infection: $E P / E N$ ) of genes that are associated with macrophage immunity and were differentially expressed between infected- and/or mock-infected macrophages

\section{Discussion}

The molecular mechanisms of VSV pathogenesis remain unclear. Multiple studies suggest that interaction with immune cells and regulation of the immune response play a role in determining the outcome of infection $(10,11,12,13,14,15)$. Because of the important roles of immune cytokines in the pathogenesis of virus infection (29) and macrophages in production of proinflammatory cytokines and their wide tissue distribution (28), VSV-infected porcine macrophages are an excellent model to extrapolate the molecular mechanisms of VSV pathogenesis. Our transcriptomic analysis shows that VSV infection induces massive ( $>10$-fold) expression of proinflammatory cytokines including IL1A and TNF especially TNF (23-fold), chemokines e.g., CCL4, CCL5 and CXCL2 (>20 times) and a PGE synthetase gene (PGTS2). CCL3, CCL4 and CCL5 share the same receptor (CCR5). Likewise, CXCL1 and CXCL3 also share the same receptor (CXCR1) with CXCL2 (39). These chemokines were also massively induced after VSV infection. High production of these cytokines and chemokines and PGE is known to induce fever $(72,73,74)$. Interestingly, LIF expression was highly upregulated after VSV infection, and LIF injection can induce fever in animals $(75,76)$. Based on these results, it is hypothesized that high fever is mainly caused by VSV-induced high production of CCR5 and CXCR1 ligands, IL1A, LIF, PGE and TNF. These cytokines, chemokines, and PGE are potent mediators of inflammation. IL1A and TNF are well-known potent proinflammatory cytokines. PGE induces vasodilatation and local recruitment of neutrophils, macrophages, and mast cells at early stages of inflammation $(77,78)$. Chemokines induced by VSV infection including CCL3, CCL4, CCL5, CCL20, CXCL1, CXCL2 and CXCL3 recruit macrophages, NK cells, neutrophils and/or Th17 cells (39). CSF3 stimulates neutrophil generation in the bone marrow (79). The expression level of CSF3 was significantly increased after VSV infection. Neutrophils are known to play a key role in clearance of viruses via phagocytosis and neutrophil extracellular traps (80). Therefore, the high production of PGE, cytokines and chemokines by VSV-infected cells could play a role in the pathogenesis within infected tissues by recruiting proinflammatory immune cells and inhibiting virus infection and spread.

TNF is one of the most potent proinflammatory cytokines, and it also induces cell death via apoptosis, necroptosis and pyroptosis pathways (81). Two genes, MAP3K8 (64) and MEFV (65), critical for TNF production were upregulated after VSV infection. Additionally, TIAL1 binds to 3' 
end noncoding sequences of several mRNA such as eIF4A, eIF4E, eEF1B and c-Myc to control the expression of translation regulatory proteins, which repress protein biosynthesis in cells responding to stress (55). TIAL1-deficient mice develop arthritis and elevated TNF expression (82). Upregulated MAP3K8 and MEFV and downregulated TIAL1 in VSV infected cells strongly support a very important role of TNF both in VSV local and systemic pathogenesis.

Other cytokines highly induced by $>10$-fold include AREG, IL-10 and LIF, which are known to have immune-suppressive effects. High levels of IL-10 suppress the innate and adaptive immune responses (83). TNF leads to IL-10 production by monocytes and together with IL-10, inhibit of CD4 T-cell expansion and function (84). LIF can suppress IFN $\gamma$ and LPS signaling $(85,86)$. LIF appears to be an immune-tolerogenic cytokine based on promoting Treg differentiation and inhibiting pro-inflammatory Th17 cell differentiation (87). Several growth factor such as VEGF and EGFs can inhibit IFNB expression (35) or suppress the anti-VSV activity of IFN $\alpha$ and IFN $\beta$ (88). The expression of VEGF and two EGFs (AREG and HBEGF) were induced after VSV infection in this study. PGE2 selectively suppresses effector functions of macrophages and neutrophils and the Th1-, CTL-, and NK cell-mediated type 1 immunity, but it promotes Th2, Th17, and regulatory T cell responses $(77,78)$. Therefore, we hypothesize that high levels of EGFs, IL-10, LIF, PGE and VEGF could play a key role in suppressing the immune response of infected and non-infected cells to facilitate VSV infection and cause disease.

Our results also indicate that VSV can evade the immune response of infected cells by various mechanisms. It is known that VSV can activate IFN response via RIG-I-MAVS and TLR4/CD14 signaling pathways to induce an antiviral response $(14,89)$. The expression of two key signaling transducers, TBK1 and MAVS $(90,91)$ in the RIG-I-MAVS signaling pathway was downregulated in VSV-infected cells compared to mock-infected cells. It has been previously reported that VSV glycoprotein binds to the TLR4/CD14 dimer leading to the induction of interferon expression, mainly mediated by IFNB via a TICAM1/TICAM2-dependent but MyD88- and NFkB-independent signaling pathway (92). In our study, the expression of TLR4 and TICAM2 was significantly suppressed by VSV infection. Infection of monocytes by VSV has been reported to suppresses type I IFN and cytokine (IL-27 and TNF) responses in a viral RNA-specific and TLR7-dependent pathway (93), and TLR7-/- mice show significantly reduced VSV titers in the draining lymph nodes and diminished viral replication in subcapsular sinus macrophages (94). Our results showed that TLR4, TLR7 expression was significantly upregulated in both VSV- and mutant-infected cells (Table 7). Therefore, VSV-altered expression of genes in the virus-sensing pathways could be another immune evading mechanism in infected cells. 
Previous studies of IFNB promoters showed that ATF2-JUN, IRF, and NFkB transcription factors regulate IFNB expression (95). The expression of ATF2 and IRF5 transcription factors was downregulated by VSV-infection. There were several downregulated signaling transducer or upregulated signaling inhibitor genes that could inhibit MAPK, NFkB, signaling pathways (Table 2). Interestingly, there were six suppressor genes of IFNB expression (AHR, ATF3, DUSP1, FOS, HES1 and PRDM1) upregulated by up to 32.8-fold in VSV-infected cells. This result supports published results that VSV suppresses the interferon response.

Our results show that VSV infection did not induce expression of other type I interferons except IFNB in pig macrophages. IFNB induction is known to induce IRF7 expression, which is needed for induction of IFNA (96). Although IFNB expression was induced in infected macrophages, the expression of IRF7 and IFNA was not increased by VSV infection. This could be explained by the suppression of interferon signaling mediated by downregulated expression of type I and II interferon receptors as shown in Table 6. This seems to a novel immune evasion mechanism of VSV in addition to the inhibition of mRNA nuclear export mediated by VSV matrix protein $(14,15)$. It has been previously reported that VSV infection inhibits the expression of interferon-stimulated genes via miR-132 to facilitate viral replication $(97,98)$. We found that miR-132 is highly upregulated by VSV infection (Table 11) which could also explain the lack of induction of interferon stimulated genes by IFNB.

Viral infections trigger three inter-connected biological processes including apoptosis, autophagy, and stress-induced unfolded protein response (UPR), which can inhibit virus replication (52). However, viruses can subvert or even manipulate these responses to promote infection, for example, VSV can delay the onset of apoptosis $(17,99)$. Our results show that multiple genes associated with these three processes were differentially expressed during VSV infection as listed in Table 10. Among these genes, GADD45B which is one of top 10 most induced genes (22.3-fold) after VSV infection, suppresses apoptosis and autophagy (51). The expression of two key regulatory genes, XBP and PPP1R15A, in the UPR pathway was reduced after VSV infection. Additionally, genes in death receptor signaling including TNFRSF1A and several signaling transducers were downregulated in VSV-infected cells, which could delay the necroptosis/apoptosis induced by high expression of TNF. These results suggest that VSV can suppress these three important innate immune mechanisms during infection.

The chemokines associated with the CCR5 receptor activate macrophages to induce proinflammatory cytokine expression $(100,101)$. Expression of CCR5 was significantly downregulated in VSV-infected macrophages, potentially reducing the immunostimulatory effect of CCR5. 
Chemokines. Additionally, high IL10 and LIF expression and downregulation of IL17RA in the infected cells could mitigate the effects of Th17 cells recruited by increased CCL20 expression. Therefore, VSV appears to be able to evade the immune response associated with chemokines induced by its infection in infected cells. Published results showed that M2 macrophages were more susceptible to infection and killing by both wildtype and a M51R-M VSV mutant than M1 macrophages (102). The M1 and M2 activation of macrophages plays important roles in the innate and adaptive immune responses. Our results suggest that VSV infection could suppress M1 activation by downregulating the expression of several purinergic receptors such as C5AR1, CCR5, IL17RA, P2RY1, P2RY6 and by upregulating IL4I1 expression.

It has been reported that VSV interferes with host gene transcription (19). Our results showed that VSV downregulated several genes of the host transcription machinery as shown in Table 11. Additionally, VSV may control host protein translation by altering expression of genes involved in maintaining mRNA stability and cap-modification, microRNA processing and protein translation. VSV encodes proteins with cap methylation activity and mutants lacking this activity show attenuated virulence (103). Our results showed downregulation of CMTR2 which could negatively impact host translation. ZFP36/TTP is known for its central role in destabilizing mRNA molecules containing class II AU-rich elements in 3' untranslated regions (56), which are frequently found in cytokine mRNA 3'-end non-coding sequences. Increased expression of this gene could destabilize cytokine mRNA and reduce its translation. Dicer1 was downregulated by VSV infection in this study, and previous works have demonstrated that Dicer1-deficient mice are hyper-susceptible to VSV infection (104). VSV infection induced a 7-fold increase of PPP1R15A (GADD34) in our study, this protein mediates dephosphorylation of eIF2 $\alpha$, which inhibits viral replication $(105,106)$ and suppresses UPR (54).

In summary, VSNJV infection significantly induced the massive expression ( $>10$-fold) of pro-inflammatory cytokines (IL1A and TNF), chemokines (CCL4, CCL20 and CXCL2) and prostaglandin E, upregulated PTGS2 and immune suppressive cytokines (IL10 and LIF), which are known to induce fever, immune suppression, and/or recruitment of immune cells. It is hypothesized that these cytokines, chemokines, and possibly PGE play important roles in local and systemic VSV pathogenesis and immune evasion. Although not significant DEG were seen between epidemic and endemic VSV strains, the endemic strain consistently induced higher expression of all upregulated cytokines and chemokines. This might help explain differences in virulence previously observed in pigs (LAURO's PAPER REF HERE) Based on our results, the mechanisms of VSV immune evasion could be achieved via suppressing (a) IFN $\beta$ expression, (b) type I and II 
interferon, IL-1 and death receptor signaling, and TLR and RIG-I signaling pathways, (c) biological processes involved in apoptosis, autophagy and unfolded protein response, (d) M1 macrophage activation, (e) host mRNA transcription, cap-methylation and stability and (f) eIF2 $\alpha$ dephosphorylation-mediated inhibition of viral protein translation. This study provides novel insights (summarized in Table 9) that warrant further investigation of VSV virulence factors and pathogenesis.

\begin{tabular}{|c|c|}
\hline Pathogenesis & Mechanism inferred from differentially expressed genes \\
\hline Systemic & $\begin{array}{l}\text { Fever: } \uparrow \text { CCLS }[3,4,5], \text { CXCLS }[1,2,3], \text { IL1A, PGTS2, TNF } \\
\text { Anorexia: } \uparrow \text { LIF, PGTS2 } \\
\text { Systemic infection restriction: } \uparrow \text { IFNB, VSV sensitive to IFN inhibition }\end{array}$ \\
\hline Local tissue & $\begin{array}{l}\text { Immune cell infiltration: } \uparrow \text { CCLs }[3,4,5,20], \text { CXCLs }[1,2,3], \text { PTGS2 } \\
\text { Inflammation: } \uparrow \text { ADM, PGTS2 } \\
\text { Vasodilatation: } \uparrow \text { PGTS2 } \\
\text { Nacroptosis/apoptosis: } \uparrow \text { TNF, } \downarrow \text { TIAL1 }\end{array}$ \\
\hline $\begin{array}{l}\text { Infected/non- } \\
\text { infected cells }\end{array}$ & $\begin{array}{l}\downarrow \text { General immune response: } \uparrow \text { IL10 } \\
\downarrow \text { Interferon response: } \uparrow \text { AREG, HBEGF, VEGF, IL1A } \\
\downarrow \text { M }, \text { neutrophils, Th1, CTL, and NK cell activities: } \uparrow \text { PGE/PGTS2 } \\
\downarrow \text { Th17 response: } \uparrow \text { LIF; } \downarrow \text { IL17RA }\end{array}$ \\
\hline \multirow[t]{2}{*}{ Infected cells } & $\begin{array}{l}\downarrow \text { IFNB production: } \uparrow \text { AHR, ATF3, DUSP1, FOS, HES1 and PRDM1; } \downarrow \text { ATF2, } \\
\downarrow \text { MAPK signaling: } \downarrow \text { MAPK4, MAPK14/p38, MAP3K18 } \\
\downarrow \text { RIG-I signaling: } \downarrow \text { IRF5, MAVS, TBK1 } \\
\downarrow \text { NFKB signaling: } \uparrow \text { NFKBIA, NFKBID, A20; } \downarrow \text { TNFSF11, } 7 \text { DEG } \\
\downarrow \text { TLR4 signaling: } \downarrow \text { BTK, TICAM2, TLR4 } \\
\downarrow \text { Interferon signaling: } \downarrow \text { IFNAR1, IFNAR2, IFNGR1, } \uparrow \text { ATF3 }\end{array}$ \\
\hline & $\begin{array}{l}\downarrow \text { Apoptosis and/or autophagy: } \uparrow \text { GADD45B, } 18 \text { DEG (Table 10) } \\
\downarrow \text { TNF signaling: } \downarrow \text { FADD, RIPK1, TNFRSF1A, TRADD; } \uparrow \text { BRE, IER3 } \\
\downarrow \text { Unfolded protein response: } \quad \downarrow \text { ERN1, XBP1, } \uparrow \text { GADD34 }\end{array}$ \\
\hline
\end{tabular}


$\downarrow$ Host mRNA cap-methylation/translation: $\downarrow$ CMTR2

$\downarrow$ Host transcription: $\downarrow 13$ DEG involved in RNA transcription (Table 11)

$\downarrow$ MФ M1 activation: $\downarrow$ C5AR1, CCR5, IL17RA, Y2RY1, Y2RY6; 个IL4I1, TNFSF9

$\uparrow$ VSV replication ( $\downarrow$ ISG expression): $\uparrow$ MIR132

$\uparrow$ VSV replication (unknown mechanisms): $\downarrow$ DICER1, $\uparrow$ TLR7

$\uparrow$ VSV protein synthesis via elF2 $\alpha$ dephosphorylation: $\uparrow$ GADD34

Table 9. Differentially expressed genes used to infer candidate mechanisms of VSV systemic and tissue pathogenesis and immune evasion in infected and non-infected cells

\section{Materials and Methods}

\subsection{Cell culture of macrophages and viruses}

Primary swine macrophage cell cultures were derived from pig peripheral blood as previously described (107). Macrophages were seeded in 6-well plates (Primaria Falcon, Becton Dickinson, Franklin Lakes, NY). VSV strains used in this study include (a) NJ0612NME6, an epidemic VS New Jersey virus (VSNJV) strain causing outbreaks in the US from 2012-2014 and isolated from a naturally infected equine in New Mexico in 2012 and (b) NJ0806VCB a VSNJV strain circulating in 2006 in an endemic area of Mexico and obtained from a naturally infected bovine in Veracruz (108). Differences between these two viruses have been reported in previous studies suggesting that NJ0612NME6 has higher virulence than NJ0806VCB in inoculated pigs (12). VSV infection experiments were conducted with three biological replicates using ex vivo cultured primary macrophages isolated from three different commercial domestic pigs. Macrophages were infected with a MOI of 10 TCID 50 of each virus, respectively. Mock infection was also performed in the cultured macrophages from these same pigs as non-infected controls.

\subsection{RNA isolation}

Total RNA was extracted from primary swine macrophage cell cultures infected with the indicated viruses, or mock infected at 5 hours post-infection. Cells were harvested and lysed with a cell lysis buffer (Qiagen, Valencia, CA) and RNA was isolated using a RNeasy mini kit (Qiagen) according to the manufacturer's instructions. The RNA quality was then determined using an Agilent 2100 bioanalyzer (Santa Clara, CA) using an RNA nanochip according to the procedures outlined by Agilent Technologies (Santa Clara, CA). RNA was quantified using a Nanodrop 1000 (Thermo Scientific, Waltham, MA).

\subsection{DNA microarray analysis}


A 44,000 (44K) porcine whole genome expression microarray was designed based on pig expressed sequences (cDNA and EST) and porcine genome sequence homologous to non-porcine sequences as reported by Zhu et al. (109). All porcine EST and RNA sequences were downloaded from the NCBI database and assembled into unique sequences using the CAP3 software program (Huang and Madan, 1999). The assembled sequences were aligned to pig genome sequences using the UCSC genome browser to select $3^{\prime}$ end RNA sequences or the genome sequences aligned with other expressed sequences of other species if no porcine expressed sequences were available. These selected sequences were used to design 60-mer oligonucleotide microarray probes with a low probability of cross-reacting with other genes and a bias to the 3 '-end of RNA sequences using Array Designer 4.0 (Applied Biosystems, Foster City, CA). Approximately 43K porcine probes were selected to synthesize a $44 \mathrm{~K}$ Agilent microarray for this study. The annotation of the porcine sequences was based on the results of a BLAST search against human reference proteins and RNA sequences downloaded from NCBI databases and manual curation based on all expressed sequences aligned in the porcine genome sequences using the UCSC genome browser. One hundred and eighty-six duplicated probes designed from all ASFV open reading frames were also included in this custom microarray.

The custom designed porcine microarrays were manufactured by Agilent Technologies and used for this study. Both ASFV-infected and mock-infected RNA samples were labeled with Cy3 and Cy5 individually using an Agilent low-input RNA labeling kit (Agilent Technologies). A Cy5-labeled ASFV-infected or mock-infected sample was co-hybridized with a Cy3-labeled mockinfected or ASFV-infected in one array, respectively, for each time point using a dye-swap design. The entire procedure of microarray analysis was conducted according to protocols, reagents and equipment provided or recommended by Agilent Technologies. Array slides were scanned using a GenePix 4000B scanner (Molecular Devices) with the GenePix Pro 6.0 software at $5 \mu \mathrm{M}$ resolution.

\subsection{Statistical and bioinformatic analyses of microarray data}

Background signal correction and data normalization of the microarray signals and statistical analysis were performed using the LIMMA package (110). $\log _{2}$ fold changes in signal intensity were used in the statistical analysis to identify deferentially expressed genes. To account for multiple testing, the p-values were adjusted using the Benjamini and Hochberg method and expressed as a false-discovery rate (FDR). The probe sequences were aligned to the porcine genome sequence displayed in the UCSC genome browser to validate the annotation by computational methods, such as BLAST. Gene expression differences with an FDR value of 0.05 or smaller and an expression difference $\geq 50 \%$ were considered statistically significant and were considered 
differentially expressed genes (DEG). Genes down- or upregulated in the infected macrophages compared to the non-infected macrophages were expressed as negative and positive values (fold), respectively.

\subsection{Pathway analyses}

The identified DEG were mapped to human reference genes. Two lists of upregulated and downregulated gene associated with human Entrez gene ID were analyzed with a NCBI online bioinformatics program (DAVID Bioinformatics Resources 6.8) to identify the biological pathways (GOTERM_BP_DIRECT, KEGG_PATHWAY and REACTOME_PATHWAY) significantly over-represented by DEG ( $\mathrm{P} \leq 0.05$ with Benjamini correction). The DEG with differential expression of 2fold or greater and 4-fold greater were used in these analyses to take the magnitudes of differentiation expression into consideration.

\subsection{Biological inference}

The biological functions of DEG in the identified over-represented pathways associated with the immune response were based on scientific publications obtained from PubMed. Biological inferences were based on (i) the immunological functions of the DEG, (ii) gene expression levels based on microarray averaged signal intensity and (iii) magnitudes (fold) of the differential expression, assuming higher mean signal intensity and larger differentially expressed genes play a bigger biological role in the gene groups. Genes with no significantly differential expression but are known to play important roles in the biological pathways associated with the significant DEG were also used as supporting evidence. Genes down- or upregulated in the VSV-infected samples compared to the mock-infected samples were expressed as negative and positive values (fold), respectively. In this study, genes differentially expressed between infected and mock infected macrophages were used to infer the molecular mechanisms of VSV pathogenesis and immune evasion.

Author Contributions: LV-S, JJZ and LR conceived and designed the experiments. LV-S performed the microarray experiments. JJZ designed the microarray analysis and performed acquisition and analysis of microarray data. JJZ, LV-S, JC, LR wrote the manuscript.

Funding: This work was performed under USDA Research Service CRIS Project No. 8064-32000-059-00D.

Institutional Review Board Statement: The animal protocol used in this study was previously reviewed and approved by the PIADC Institutional Animal Care and Use Committee of the US Departments of Agriculture and Homeland Security (protocol number \#245-200 05-14R; approved 07/12/2021). 
Data Availability Statement: The microarray raw data are in the process of submitting to NCBI database. The data sets will be available to the public if this manuscript is accepted for publication.

Acknowledgments: We thank Dr. Manuel B. Borca at PIADC for kindly providing with the cell cutures of macrophages for this study. This research was supported in part by an appointment to PIADC Research Participation Program administered by the Oak Ridge Institute for Science and Education (ORISE) through an interagency agreement between the U.S. Department of Energy (DOE) and the U.S. Department of Agriculture (USDA). ORISE is managed by ORAU under DOE contract number DE-SC0014664. All opinions expressed in this paper are the author's and do not necessarily reflect the policies and views of USDA, ARS, or ORAU/ORISE.

Conflicts of Interest: The authors declare that the research was conducted in the absence of any commercial or financial relationships that could be construed as a potential conflict of interest.

\section{References}

1. Wagner, R. R., and Rose, J. K. (1996). Rhabdoviridae: The viruses and their replication. In "Fields' Virology" (B. N. Fields, D. M. Knipe, P. M. Howley, R. M. Chanock, M. S. Hirsh, J. L. Melnick, T. P. Monath, B. Roizman, and S. E. Straus, Eds.), Vol. 2, 3rd ed., pp. 1121-1136. Lippincott-Raven, Philadelphia.

2. Dietzgen R. G. (2012). "Morphology. Genome organization, transcription and replication of rhabdoviruses," in Rhabdoviruses: Molecular Taxonomy, Evolution, Genomics, Ecology, Host-Vector Interactions, Cytopathology and Control, eds Dietzgen R. G., Kuzmin I. V. (Poole: Caister Academic Press; ).

3. Spiropoulou CF, Nichol ST. A small highly basic protein is encoded in overlapping frame within the $P$ gene of vesicular stomatitis virus. J Virol. 1993;67(6):3103-3110. doi:10.1128/JVI.67.6.3103-3110.1993.

4. Rodríguez LL. Emergence and re-emergence of vesicular stomatitis in the United States. Virus Res. 2002;85(2):211-219. doi:10.1016/s0168-1702(02)00026-6

5. Mead DG, Gray EW, Noblet R, Murphy MD, Howerth EW, Stallknecht DE. Biological transmission of vesicular stomatitis virus (New Jersey serotype) by Simulium vittatum (Diptera: Simuliidae) to domestic swine (Sus scrofa). J Med Entomol. 2004;41(1):78-82. doi:10.1603/0022-2585-41.1.78.

6. Finkelshtein D, Werman A, Novick D, Barak S, Rubinstein M. LDL receptor and its family members serve as the cellular receptors for vesicular stomatitis virus. Proc Natl Acad Sci U S A. 2013 Apr 30;110(18):7306-11.

7. Hastie E1, Cataldi M, Marriott I, Grdzelishvili VZ. Understanding and altering cell tropism of vesicular stomatitis virus. Virus Res. 2013 Sep;176(1-2):16-32. doi: 10.1016/j.virusres.2013.06.003. Epub 2013 Jun 22.

8. Publicover J1, Ramsburg E, Robek M, Rose JK. Rapid pathogenesis induced by a vesicular stomatitis virus matrix protein mutant: viral pathogenesis is linked to induction of tumor necrosis factor alpha. J Virol. 2006 Jul;80(14):7028-36.

9. Iannacone M1, Moseman EA, Tonti E, Bosurgi L, Junt T, Henrickson SE, Whelan SP, Guidotti LG, von Andrian UH. Subcapsular sinus macrophages prevent CNS invasion on peripheral infection with a neurotropic virus. Nature. 2010 Jun 24;465(7301):1079-83. doi: 10.1038/nature09118. 
10. Scherer CF, O'Donnell V, Golde WT, Gregg D, Estes DM, Rodriguez LL. Vesicular stomatitis New Jersey virus (VSNJV) infects keratinocytes and is restricted to lesion sites and local lymph nodes in the bovine, a natural host. Vet Res. 2007;38(3):375-390. doi:10.1051/vetres:2007001.

11. Sun G1, Fang X2, Wu H1, Zhou X1, Ke Y1, Sun T3. Porcine monocyte-derived dendritic cells can be differentially activated by vesicular stomatitis virus and its matrix protein mutants. Vet Microbiol. 2018 Jun;219:30-39.

12. Velazquez-Salinas L, Pauszek SJ, Stenfeldt C, et al. Increased Virulence of an Epidemic Strain of Vesicular Stomatitis Virus Is Associated With Interference of the Innate Response in Pigs. Front Microbiol. 2018;9:1891. Published 2018 Aug 15. doi:10.3389/fmicb.2018.01891.

13. Velazquez-Salinas L, Pauszek SJ, Holinka LG, Gladue DP, Rekant SI, Bishop EA, et al. A Single Amino Acid Substitution in the Matrix Protein (M51R) of Vesicular Stomatitis New Jersey Virus Impairs Replication in Cultured Porcine Macrophages and Results in Significant Attenuation in Pigs. Front Microbiol. 2020;11:1123.

14. Faul EJ, Lyles DS, Schnell MJ. Interferon response and viral evasion by members of the family rhabdoviridae. Viruses. 2009 Dec;1(3):832-51.

15. Rieder M, Conzelmann KK. Rhabdovirus evasion of the interferon system. J Interferon Cytokine Res. 2009 Sep;29(9):499-509.

16. Jayakar HR, Whitt MA. Identification of two additional translation products from the matrix (M) gene that contribute to vesicular stomatitis virus cytopathology. J Virol. 2002 Aug;76(16):8011-8.

17. Kopecky SA, Willingham MC, Lyles DS. Matrix protein and another viral component contribute to induction of apoptosis in cells infected with vesicular stomatitis virus. J Virol. 2001 Dec;75(24):12169-81.

18. Black BL1, Lyles DS. Vesicular stomatitis virus matrix protein inhibits host cell-directed transcription of target genes in vivo. J Virol. 1992 Jul;66(7):4058-64.

19. Yuan H1, Yoza BK, Lyles DS. Inhibition of host RNA polymerase II-dependent transcription by vesicular stomatitis virus results from inactivation of TFIID. Virology. 1998 Nov 25;251(2):383-92.

20. von Kobbe C, van Deursen JM, Rodrigues JP, Sitterlin D, Bachi A, Wu X, Wilm M, Carmo-Fonseca M, Izaurralde E. Vesicular stomatitis virus matrix protein inhibits host cell gene expression by targeting the nucleoporin Nup98. Mol Cell. 2000 Nov;6(5):1243-52.

21. Rajani KR1, Pettit Kneller EL, McKenzie MO, Horita DA, Chou JW, Lyles DS. Complexes of vesicular stomatitis virus matrix protein with host Rae1 and Nup98 involved in inhibition of host transcription. PLoS Pathog. 2012 Sep;8(9):e1002929.

22. Pan W1, Song D1, He W1, Lu H2, Lan Y1, Tong J1, Gao F3, Zhao K4. The matrix protein of vesicular stomatitis virus inhibits host-directed transcription of target genes via interaction with the TFIIH subunit p8. Vet Microbiol. 2017 Sep;208:82-88.

23. Petersen JM1, Her LS, Varvel V, Lund E, Dahlberg JE. The matrix protein of vesicular stomatitis virus inhibits nucleocytoplasmic transport when it is in the nucleus and associated with nuclear pore complexes. Mol Cell Biol. 2000 Nov;20(22):8590-601.

24. Varble AJ1, Ried CD1, Hammond WJ1, Marquis KA1, Woodruff MC1, Ferran MC2. The vesicular stomatitis virus matrix protein inhibits NF- $\kappa$ B activation in mouse L929 cells. Virology. 2016 Dec;499:99-104.

25. Ahmed M1, McKenzie MO, Puckett S, Hojnacki M, Poliquin L, Lyles DS. Ability of the matrix protein of vesicular stomatitis virus to suppress beta interferon gene expression is genetically correlated with the inhibition of host RNA and protein synthesis. J Virol. 2003 Apr;77(8):4646-57. 
26. Kandasamy RK, Vladimer GI, Snijder B, et al. A time-resolved molecular map of the macrophage response to VSV infection. NPJ Syst Biol Appl. 2016;2:16027. Published 2016 Oct 27. doi:10.1038/npjsba.2016.27.

27. Russell TM. 2018. Theses: Transcriptome-Wide Analysis of VSV Strains with Varying Ability to Block NF- $\kappa B$. Rochester Institute of Technology Scholar Works.

28. Franken L, Schiwon M, Kurts C. Macrophages: sentinels and regulators of the immune system. Cell Microbiol. 2016;18(4):475-487. doi:10.1111/cmi.12580

29. Dantzer R1. Cytokine, sickness behavior, and depression. Immunol Allergy Clin North Am. 2009 May;29(2):247-64. doi: 10.1016/j.iac.2009.02.002.

30. Zhou, Q., Lavorgna, A., Bowman, M., Hiscott, J., Harhaj, E.W., 2015. Aryl Hydrocarbon Receptor Interacting Protein Targets IRF7 to Suppress Antiviral Signaling and the Induction of Type I Interferon. J Biol Chem 290, 14729-14739.

31. Yamada, T., Horimoto, H., Kameyama, T., Hayakawa, S., Yamato, H., Dazai, M., Takada, A., Kida, H., Bott, D., Zhou, A.C., Hutin, D., Watts, T.H., Asaka, M., Matthews, J., Takaoka, A., 2016. Constitutive aryl hydrocarbon receptor signaling constrains type I interferon-mediated antiviral innate defense. Nat Immunol 17, 687-694.

32. Labzin LI, Schmidt SV, Masters SL, Beyer M, Krebs W, Klee K, Stahl R, Lütjohann D, Schultze JL, Latz E, De Nardo D. ATF3 Is a Key Regulator of Macrophage IFN Responses. J Immunol. 2015 Nov 1;195(9):4446-55.

33. Köröskényi K1, Kiss B1, Szondy Z2. Adenosine A2A receptor signaling attenuates LPS-induced proinflammatory cytokine formation of mouse macrophages by inducing the expression of DUSP1. Biochim Biophys Acta. 2016 Jul;1863(7 Pt A):1461-71.

34. Ray N1, Kuwahara M, Takada Y, Maruyama K, Kawaguchi T, Tsubone H, Ishikawa H, Matsuo K. c-Fos suppresses systemic inflammatory response to endotoxin. Int Immunol. 2006 May;18(5):671-7.

35. Ning F1,2,3, Li X1,3, Yu L1,2,3, Zhang B1,3, Zhao Y4, Liu Y5, Zhao B6,7, Shang Y8, Hu X9,3. Hes1 attenuates type I IFN responses via VEGF-C and WDFY1. J Exp Med. 2019 Jun 3;216(6):1396-1410.

36. Keller $\mathrm{AD}$, Maniatis $\mathrm{T}$. Identification and characterization of a novel repressor of beta-interferon gene expression. Genes Dev. 1991 May;5(5):868-79.

37. Mora-López F1, Pedreño-Horrillo N, Delgado-Pérez L, Brieva JA, Campos-Caro A. Transcription of PRDM1, the master regulator for plasma cell differentiation, depends on an SP1/SP3/EGR-1 GC-box. Eur J Immunol. 2008 Aug;38(8):2316-24.

38. Das T1, Chen Z1, Hendriks RW1, Kool M1. A20/Tumor Necrosis Factor $\alpha$-Induced Protein 3 in Immune Cells Controls Development of Autoinflammation and Autoimmunity: Lessons from Mouse Models. Front Immunol. 2018 Feb 21;9:104.

39. Griffith JW1, Sokol CL, Luster AD. Chemokines and chemokine receptors: positioning cells for host defense and immunity. Annu Rev Immunol. 2014;32:659-702.

40. Kataoka T1, Holler N, Micheau O, Martinon F, Tinel A, Hofmann K, Tschopp J. Bcl-rambo, a novel Bcl-2 homologue that induces apoptosis via its unique C-terminal extension. J Biol Chem. 2001 Jun 1;276(22):1954854.

41. Singh P1, Ravanan P1, Talwar P1. Death Associated Protein Kinase 1 (DAPK1): A Regulator of Apoptosis and Autophagy. Front Mol Neurosci. 2016 Jun 23;9:46.

42. García-Domingo D1, Ramírez D, González de Buitrago G, Martínez-A C. Death inducer-obliterator 1 triggers apoptosis after nuclear translocation and caspase upregulation. Mol Cell Biol. 2003 May;23(9):3216-25. 
43. Li J1, Zhou Q1, Yang T2, Li Y2, Zhang Y3, Wang J4, Jiao Z5. SGK1 inhibits PM2.5-induced apoptosis and oxidative stress in human lung alveolar epithelial A549 cells. Biochem Biophys Res Commun. 2018 Feb 19;496(4):1291-1295.

44. Chen C1, Edelstein LC, Gélinas C. The Rel/NF-kappaB family directly activates expression of the apoptosis inhibitor Bcl-x(L). Mol Cell Biol. 2000 Apr;20(8):2687-95.

45. Gu C1, Castellino A, Chan JY, Chao MV. BRE: a modulator of TNF-alpha action. FASEB J. 1998 Sep;12(12):11018.

46. Akilov OE1, Wu MX, Ustyugova IV, Falo LD Jr, Geskin LJ. Resistance of Sézary cells to TNF- $\alpha$-induced apoptosis is mediated in part by a loss of TNFR1 and a high level of the IER3 expression. Exp Dermatol. 2012 Apr;21(4):287-92.

47. Dunlop EA, Seifan S, Claessens T, Behrends C, Kamps MA, Rozycka E, Kemp AJ, Nookala RK, Blenis J, Coull BJ, Murray JT, van Steensel MA, Wilkinson S, Tee AR. FLCN, a novel autophagy component, interacts with GABARAP and is regulated by ULK1 phosphorylation. Autophagy. 2014 Oct 1;10(10):1749-60.

48. Li L1, Wang G1, Hu JS1, Zhang GQ1, Chen HZ1, Yuan Y2, Li YL1, Lv XJ1, Tian FY1, Pan SH1,3, Bai XW1, Sun B4. RB1CC1-enhanced autophagy facilitates PSCs activation and pancreatic fibrogenesis in chronic pancreatitis. Cell Death Dis. 2018 Sep 20;9(10):952.

49. Morgan NE, Cutrona MB, Simpson JC. Multitasking Rab Proteins in Autophagy and Membrane Trafficking: A Focus on Rab33b. Int J Mol Sci. 2019 Aug 12;20(16).

50. Luo S1, Rubinsztein DC. BCL2L11/BIM: a novel molecular link between autophagy and apoptosis. Autophagy. 2013 Jan;9(1):104-5.

51. He G1, Xu W2, Tong L1, Li S2, Su S2, Tan X1, Li C3. Gadd45b prevents autophagy and apoptosis against rat cerebral neuron oxygen-glucose deprivation/reperfusion injury. Apoptosis. 2016 Apr;21(4):390-403.

52. Mehrbod P1, Ande SR2, Alizadeh J3,4,5, Rahimizadeh S6, Shariati A3, Malek H7, Hashemi M8, Glover KKM9, Sher AA9, Coombs KM4,9,10, Ghavami S3,4,5,11. The roles of apoptosis, autophagy and unfolded protein response in arbovirus, influenza virus, and HIV infections. Virulence. 2019 Dec;10(1):376-413.

53. Chen Y1, Brandizzi F. IRE1: ER stress sensor and cell fate executor. Trends Cell Biol. 2013 Nov;23(11):547-55.

54. Novoa I, Zeng H, Harding HP, Ron D. Feedback inhibition of the unfolded protein response by GADD34mediated dephosphorylation of eIF2alpha. J Cell Biol. 2001 May 28;153(5):1011-22.

55. Mazan-Mamczarz K1, Lal A, Martindale JL, Kawai T, Gorospe M. Translational repression by RNA-binding protein TIAR. Mol Cell Biol. 2006 Apr;26(7):2716-27.

56. Schaljo, B.; Kratochvill, F.; Gratz, N.; Sadzak, I.; Sauer, I.; Hammer, M.; Vogl, C.; Strobl, B.; Muller, M.; Blackshear, P.J.; et al. Tristetraprolin is required for full anti-inflammatory response of murine macrophages to IL-10. J. Immunol. 2009, 183, 1197-1206.

57. Önal U1, Valenzuela-Sánchez F2, Vandana KE3, Rello J4. Mid-Regional Pro-Adrenomedullin (MR-proADM) as a Biomarker for Sepsis and Septic Shock: Narrative Review. Healthcare (Basel). 2018 Sep 3;6(3).

58. Kawahara K, Hohjoh H, Inazumi T, Tsuchiya S, Sugimoto Y. Prostaglandin E2-induced inflammation: Relevance of prostaglandin E receptors. Biochim Biophys Acta. 2015;1851(4):414-421.

59. Wei W1, Jiao Y, Postlethwaite A, Stuart JM, Wang Y, Sun D, Gu W. Dual-specificity phosphatases 2: surprising positive effect at the molecular level and a potential biomarker of diseases. Genes Immun. 2013 Jan;14(1):1-6.

60. Ruan Z, Wang S, Yu W, Deng F. LncRNA MALAT1 aggravates inflammation response through regulating PTGS2 by targeting miR-26b in myocardial ischemia-reperfusion injury. Int J Cardiol. 2019;288:122. 
61. Bohlson SS1, O'Conner SD1, Hulsebus HJ1, Ho MM2, Fraser DA2. Complement, c1q, and c1q-related molecules regulate macrophage polarization. Front Immunol. 2014 Aug 21;5:402.

62. Li R1, Tan B1, Yan Y1, Ma X1, Zhang N1, Zhang Z2, Liu M1, Qian M3, Du B3. Extracellular UDP and P2Y6 function as a danger signal to protect mice from vesicular stomatitis virus infection through an increase in IFN$\beta$ production. J Immunol. 2014 Nov 1;193(9):4515-26.

63. Yue Y, Huang W, Liang J, Guo J, Ji J, Yao Y, Zheng M, Cai Z, Lu L, Wang J. IL4I1 Is a Novel Regulator of M2 Macrophage Polarization That Can Inhibit T Cell Activation via L-Tryptophan and Arginine Depletion and IL10 Production. PLoS One. 2015 Nov 24;10(11):e0142979.

64. Mielke LA, Elkins KL, Wei L, et al. Tumor progression locus 2 (Map3k8) is critical for host defense against Listeria monocytogenes and IL-1 beta production. J Immunol. 2009;183(12):7984-7993.

65. Chae JJ, Wood G, Richard K, Jaffe H, Colburn NT, Masters SL et al. The familial Mediterranean fever protein, pyrin, is cleaved by caspase-1 and activates NF-kappaB through its N-terminal fragment. Blood 2008; 112: 1794-1803.Chan SW1. The unfolded protein response in virus infections. Front Microbiol. 2014 Sep 30;5:518.

66. Ko CY1,2, Chang WC3, Wang JM4,5,6,7. Biological roles of CCAAT/Enhancer-binding protein delta during inflammation. J Biomed Sci. 2015 Jan 16;22:6. doi: 10.1186/s12929-014-0110-2.

67. Zhang, F.; Tang, B.; Zhang, Z.; Xu, D.; Ma, G. DUSP6 Inhibitor (E/Z)-BCI Hydrochloride Attenuates Lipopolysaccharide-Induced Inflammatory Responses in Murine Macrophage Cells via Activating the Nrf2 Signaling Axis and Inhibiting the NF-kappaB Pathway. Inflammation. 2019 Apr;42(2):672-681.

68. Hamada M1,2, Tsunakawa Y1,3, Jeon H1,2, Yadav MK1,3, Takahashi S1,2. Role of MafB in macrophages. Exp Anim. 2020 Jan 29;69(1):1-10.

69. Ma Q, Liu Y, Chen L. JIP3 deficiency attenuates cardiac hypertrophy by suppression of JNK pathway. Biochem Biophys Res Commun. 2018 Sep 3;503(1):1-7.

70. Kotrys AV1, Cysewski D1, Czarnomska SD1, Pietras Z1,2, Borowski LS1,3, Dziembowski A1,3, Szczesny RJ1. Quantitative proteomics revealed C6orf203/MTRES1 as a factor preventing stress-induced transcription deficiency in human mitochondria. Nucleic Acids Res. 2019 Aug 22;47(14):7502-7517. doi: 10.1093/nar/gkz542.

71.

72. Soares DM1, Hiratsuka Veiga-Souza F, Fabrício AS, Javier Miñano F, Petto Souza GE. CCL3/macrophage inflammatory protein-1alpha induces fever and increases prostaglandin E2 in cerebrospinal fluid of rats: effect of antipyretic drugs. Brain Res. 2006 Sep 13;1109(1):83-92.

73. Soares DM1, Machado RR, Yamashiro LH, Melo MC, Souza GE. Cytokine-induced neutrophil chemoattractant (CINC)-1 induces fever by a prostaglandin-dependent mechanism in rats. Brain Res. 2008 Oct 3;1233:79-88.

74. Lachmann HJ. Periodic fever syndromes. Best Pract Res Clin Rheumatol. 2017 Aug;31(4):596-609.

75. Chesnokova, V., and S. Melmed. 2000. Leukemia inhibitory factor mediates the hypothalamic pituitary adrenal axis response to inflammation. Endocrinology 141:4032-4040.

76. Daniel JA, Whitlock BK, Marks DL, Gard JA, Sartin JL. Leukemia inhibitory factor as a mediator of lipopolysaccharide effects on appetite and selected hormones and metabolites. J Anim Sci. 2016 Jul;94(7):278997. doi: 10.2527/jas.2016-0396.

77. Kalinski P1. Regulation of immune responses by prostaglandin E2. J Immunol. 2012 Jan 1;188(1):21-8. doi: 10.4049/jimmunol.1101029.

78. Sander WJ, O'Neill HG, Pohl CH. Prostaglandin E2 As a Modulator of Viral Infections. Front Physiol. 2017 Feb $14 ; 8: 89$. 
79. Dwivedi P1, Greis KD2. Granulocyte colony-stimulating factor receptor signaling in severe congenital neutropenia, chronic neutrophilic leukemia, and related malignancies. Exp Hematol. 2017 Feb;46:9-20. doi: 10.1016/j.exphem.2016.10.008. Epub 2016 Oct 24.

80. Stegelmeier AA, van Vloten JP, Mould RC, Klafuric EM, Minott JA, Wootton SK, et al. 2019. Myeloid cells during viral infections and inflammation. Viruses.;11(2).

81. Wajant H, Siegmund D. TNFR1 and TNFR2 in the Control of the Life and Death Balance of Macrophages. Front Cell Dev Biol. 2019;7:91. Published 2019 May 29. doi:10.3389/fcell.2019.00091.

82. Sánchez-Jiménez C1, Izquierdo JM. T-cell intracellular antigens in health and disease. Cell Cycle. 2015;14(13):2033-43.

83. Rojas JM1, Avia M1, Martín V1, Sevilla N1. IL-10: A Multifunctional Cytokine in Viral Infections. J Immunol Res. 2017;2017:6104054.

84. Said EA, Dupuy FP, Trautmann L, Zhang Y, Shi Y, El-Far M, Hill BJ, Noto A, Ancuta P, Peretz Y, Fonseca SG, Van Grevenynghe J, Boulassel MR, Bruneau J, Shoukry NH, Routy JP, Douek DC, Haddad EK, Sekaly RP (April 2010). "Programmed death-1-induced interleukin-10 production by monocytes impairs CD4+ T cell activation during HIV infection". Nat. Med. 16 (4): 452-9.

85. Weber MA1, Schnyder-Candrian S, Schnyder B, Quesniaux V, Poli V, Stewart CL, Ryffel B. Endogenous leukemia inhibitory factor attenuates endotoxin response. Lab Invest. 2005 Feb;85(2):276-84.

86. Davis SM1, Collier LA1, Winford ED2, Leonardo CC3, Ajmo CT Jr3, Foran EA4, Kopper TJ5,6, Gensel JC5,6, Pennypacker KR7,8. Leukemia inhibitory factor modulates the peripheral immune response in a rat model of emergent large vessel occlusion. J Neuroinflammation. 2018 Oct 15;15(1):288.

87. Metcalfe SM. LIF in the regulation of T-cell fate and as a potential therapeutic. Genes and immunity. 2011; 12:157-68.

88. Takahara T, Fukuyama Y, Saito S, Ogino T, Miyajima N, Kohase M. Il-1, EGF, and HGF suppress the antiviral activity of interferon in primary monkey hepatic parenchymal cells. Jpn J Infect Dis. 1999 Apr;52(2):45-8.

89. Kato, H.; Takeuchi, O.; Sato, S.; Yoneyama, M.; Yamamoto, M.; Matsui, K.; Uematsu, S.; Jung, A.; Kawai, T.; Ishii, K.J.; Yamaguchi, O.; Otsu, K.; Tsujimura, T.; Koh, C.S.; Reis e Sousa, C.; Matsuura, Y.; Fujita, T.; Akira, S. Differential roles of MDA5 and RIG-I helicases in the recognition of RNA viruses. Nature 2006, 441, 101-105.

90. Meylan, E.; Curran, J.; Hofmann, K.; Moradpour, D.; Binder, M.; Bartenschlager, R.; Tschopp, J. Cardif is an adaptor protein in the RIG-I antiviral pathway and is targeted by hepatitis C virus. Nature 2005, 437, 1167-1172.

91. Liu XY1, Chen W, Wei B, Shan YF, Wang C. IFN-induced TPR protein IFIT3 potentiates antiviral signaling by bridging MAVS and TBK1. J Immunol. 2011 Sep 1;187(5):2559-68.

92. Georgel P, Jiang Z, Kunz S, Janssen E, Mols J, Hoebe K, Bahram S, Oldstone MB, Beutler B. Vesicular stomatitis virus glycoprotein G activates a specific antiviral Toll-like receptor 4-dependent pathway. Virology. 2007 Jun 5;362(2):304-13.

93. de Marcken M1, Dhaliwal K1, Danielsen AC1, Gautron AS1, Dominguez-Villar M2. TLR7 and TLR8 activate distinct pathways in monocytes during RNA virus infection. Sci Signal. 2019 Oct 29;12(605).

94. Solmaz G, Puttur F, Francozo M, Lindenberg M, Guderian M, Swallow M, Duhan V, Khairnar V, Kalinke U, Ludewig B, Clausen BE, Wagner H, Lang KS, Sparwasser TD. TLR7 Controls VSV Replication in CD169+ SCS Macrophages and Associated Viral Neuroinvasion. Front Immunol. 2019 Mar 15;10:466.

95. Honda K, Takaoka A, Taniguchi T. Type I interferon [corrected] gene induction by the interferon regulatory factor family of transcription factors. Immunity. 2006 Sep;25(3):349-60. 
96. Marié I, J E Durbin, D E Levy. Differential viral induction of distinct interferon-alpha genes by positive feedback through interferon regulatory factor-7. EMBO J. 1998 Nov 16; 17(22): 6660-6669.

97. Lagos D1, Pollara G, Henderson S, Gratrix F, Fabani M, Milne RS, Gotch F, Boshoff C. miR-132 regulates antiviral innate immunity through suppression of the p300 transcriptional co-activator. Nat Cell Biol. 2010 May;12(5):513-9.

98. Zhang F, Lin X, Yang X, Lu G, Zhang Q, Zhang C. MicroRNA-132-3p suppresses type I IFN response through targeting IRF1 to facilitate H1N1 influenza A virus infection. Biosci Rep. 2019 Dec 20;39(12).

99. Chan SW. The unfolded protein response in virus infections. Front Microbiol. 2014;5:518. Published 2014 Sep 30. doi:10.3389/fmicb.2014.00518.

100. Aliberti J1, Reis e Sousa C, Schito M, Hieny S, Wells T, Huffnagle GB, Sher A. CCR5 provides a signal for microbial induced production of IL-12 by CD8 alpha+ dendritic cells. Nat Immunol. 2000 Jul;1(1):83-7.

101. Shaheen ZR1, Christmann BS2, Stafford JD1, Moran JM2, Buller RML3, Corbett JA1. CCR5 is a required signaling receptor for macrophage expression of inflammatory genes in response to viral double-stranded RNA. Am J Physiol Regul Integr Comp Physiol. 2019 May 1;316(5):R525-R534.

102. Polzin M, McCanless J, Owen S, Sizemore D, Lucero E, Fuller R, Neufeld HS, Seals DF, Ahmed M. Oncolytic vesicular stomatitis viruses selectively target M2 macrophages. Virus Res. 2020 Apr 28:197991.

103. Ma Y1, Wei Y, Zhang X, Zhang Y, Cai H, Zhu Y, Shilo K, Oglesbee M, Krakowka S, Whelan SP, Li J. mRNA cap methylation influences pathogenesis of vesicular stomatitis virus in vivo. J Virol. 2014 88(5):2913-26.

104. Otsuka M, Jing Q, Georgel P, New L, Chen J, Mols J, Kang YJ, Jiang Z, Du X, Cook R, Das SC, Pattnaik AK, Beutler B, Han J. Hypersusceptibility to vesicular stomatitis virus infection in Dicer1-deficient mice is due to impaired miR24 and miR93 expression. Immunity. 2007 Jul;27(1):123-34.

105. Connor J. H., Lyles D. S. (2005). Inhibition of host and viral translation during vesicular stomatitis virus infection. eIF2 is responsible for the inhibition of viral but not host translation. J. Biol. Chem. 280, 13512-13519.

106. Baltzis D1, Qu LK, Papadopoulou S, Blais JD, Bell JC, Sonenberg N, Koromilas AE. Resistance to vesicular stomatitis virus infection requires a functional cross talk between the eukaryotic translation initiation factor 2alpha kinases PERK and PKR. J Virol. 2004 Dec;78(23):12747-61.

107. Zsak, L., et al., An African swine fever virus virulence-associated gene NL-S with similarity to the herpes simplex virus ICP34.5 gene. J Virol, 1996. 70(12): p. 8865-71.

108. Velazquez-Salinas, L., Pauszek, S.J., Verdugo-Rodriguez, A., Rodriguez, L.L., 2018. Complete Genome Sequences of Two Vesicular Stomatitis New Jersey Viruses Representing the 2012 U.S. Epidemic Strain and Its Closest Relative Endemic Strain from Southern Mexico. Genome Announc 6.

109. Zhu JJ, Ramanathan P, Bishop EA, O'Donnell V, Gladue DP, Borca MV. Mechanisms of African swine fever virus pathogenesis and immune evasion inferred from gene expression changes in infected swine macrophages. PLoS One. 2019;14(11):e0223955. Published 2019 Nov 14. doi:10.1371/journal.pone.0223955.

110. Huang X, Madan A. CAP3: A DNA sequence assembly program. Genome Res. 1999;9(9):868-77. doi: 10.1101/gr.9.9.868.

111. Smyth G.. Gentleman R., Carey V., Dudoit S., Irizarry R., Huber W.. Limma: linear models for microarray data, Bioinformatics and Computational Biology Solutions Using R and Bioconductor., 2005New YorkSpringer(pg. 397-420) 